\title{
Effect of Postnatal Exercises on Quality of Life in Immediate Postpartum Mothers: A Clinical Trial
}

\author{
${ }^{1}$ Arati V Mahishale, ${ }^{2}$ Lume Pereira Antonyna Maria Ulorica, ${ }^{3}$ Hema S Patil
}

\begin{abstract}
Objective: Women are potentially susceptible to complications during postpartum period which may affect their physical, mental and social wellbeing. It is essential to deliver appropriate postpartum care in immediate postpartum mothers to improve the general wellbeing. Postnatal exercises are administered in routine clinical practice for early mobility and postnatal recovery. The present study aimed to assess the effect of postnatal exercise on postpartum maternal physical, mental, social and general wellbeing in immediate postpartum women.
\end{abstract}

Materials and methods: Setting-Tertiary care hospital; Subjects-33 immediate postpartum women with vaginal delivery were recruited after obtaining an informed consent and clearance from the institutional ethical committee; Treatmentpostnatal exercises namely aerobic exercises, general body strengthening exercises, and pelvic floor muscle exercises were given from 2 nd to 4 th day postpartum, twice per day each session lasting for 30 minutes each; Tool-the short-form (36) questionnaire was administered as an outcome measure; statistical analysis was done using SPSS version 16.

Results: The results showed statistically significant difference in quality of life according to the short form (36) scores on 4 th day postintervention as compared to 2 nd day preintervention with $p<0.001$ in all domains.

Conclusion: Postnatal exercises administered during immediate postpartum period helps improve the quality of life by improving physical, mental, social and general wellbeing.

Keywords: Postpartum period, Postnatal exercises, Quality of life, SF-36.

How to cite this article: Mahishale AV, Maria Vlorica LPA, Patil HS. Effect of Postnatal Exercises on Quality of Life in Immediate Postpartum Mothers: A Clinical Trial. J South Asian Feder Obst Gynae 2014;6(1):11-14.

Source of support: Nil

Conflict of interest: None

\footnotetext{
${ }^{1,3}$ Assistant Professor, ${ }^{2}$ Student (1st Year)

1,2Department of Obstetrics, Gynecology and Physiotherapy Institute of Physiotherapy, KLE University, Belgaum, Karnataka India

${ }^{3}$ Department of Obstetrics and Gynecology, Jawaharlal Nehru Medical College, KLE University, Belgaum, Karnataka, India

Corresponding Author: Hema S Patil, Assistant Professor Department of Obstetrics and Gynecology, Jawaharlal Nehru Medical College, KLE University, Nehru Nagar Belgaum-590010, Karnataka, India, Phone: +91-9164342888 e-mail: hemabanad@yahoo.com
}

\section{INTRODUCTION}

The postpartum period starts following child birth and ends at 42 days is associated with complications like postpartum hemorrhage, deep vein thrombosis, pulmonary embolism, gravitational edema, puerperal infection, breast feeding problems, postural difficulties and backache and so she should be taken care of ${ }^{1-5}$ It is evident that delivering proper care to improve the health and quality of life of women is a must, that needs a regular evidence-based exercise program for postpartum care. ${ }^{3,4}$ ACOG in 2002, recommended exercises for 30 minutes a day during pregnancy and the postpartum period for additional health benefits. ${ }^{6,7}$ Aerobic exercises performed for 6 to 8 weeks 4 to 5 times per week would be a key factor in maintaining the normal and maximum function. ${ }^{4,8}$ In 1999, Sampselle et al concluded that women who participate in physical exercises in postpartum period enjoy advantages such as less weight retention, and higher delivery adjustment scores. ${ }^{4,9-11}$ The SF-36 is a measure of health and is commonly used in health economics as a variable in the quality-adjusted life year calculation to determine the cost effectiveness of a health treatment. ${ }^{12}$ Although postpartum exercises are well-accepted and implemented during immediate postpartum period, the effect of the same on quality of life has not been evaluated in our institute. Hence, the current study was carried out to study the effect of immediate postpartum exercises on maternal quality of life.

\section{MATERIALS AND METHODS}

This study was conducted at KLE's Dr Prabhakar Kore Hospital and Medical Research Centre, Belgaum. Women with vaginal delivery between 24 and 48 hours postpartum were recruited for the study. It was a single group pre-post experimental study design. Data was collected at a tertiary care centre, Karnataka, from November 2012 to January 2013, nonprobability design using convenience sampling was used. Total 33 subjects were recruited. Inclusion criteria: (1) women aged between 18 and 35 years, (2) primi and multiparous women; Exclusion criteria, (1) women not involved in any exercise regimen during pregnancy, (2) obstetric complications, like postpartum hemorrhage - primary and secondary, pre-eclampsia, abruption, placenta previa and marked rectus diastasis, ${ }^{8}(3)$ other medical conditions like 
hypertension, cardiac disease, diabetes, (4) systemic illness or infections, (5) pelvic diastasis study was approved by the Institutional Ethical Review Committee. Women fulfilling the eligibility criteria were recruited for the study and written informed consent was taken from the study women prior to the commencement of study. Demographic details like name, age, height, weight, address and contact details were recorded. Intervention included 10 minutes of brisk walking and strengthening exercises for muscles namely neck flexors, extensors, side flexors, rotators, abdominals, scapular retractors, depressors, shoulder external rotators, hip extensors, knee extensors and flexors and ankle dorsiflexors and pelvic floor muscle exercises. ${ }^{1,3,8}$ Intervention was carried out for three consecutive days beginning from the second day postpartum to fourth day postpartum period twice daily for a duration of 30 minutes per session. The SF-36 questionnaire was used as an outcome measure. The SF-36 is a measure of health and is commonly used in health economics as a variable in the quality-adjusted life year calculation to determine the cost effectiveness of a health treatment. It consists of 8 scaled scores which are weighted sums of the questions in their section. Each scale is directly transformed into a 0-100 scale on the assumption that each question carries equal weight. The 8 sections are vitality, physical functioning, bodily pain, general health perceptions, and physical role functioning, emotional role functioning, social role functioning and mental health. It evaluates individual patient's health status, monitoring and comparing disease burden. SF-36 was administered on the 1 st day pre-intervention and on the 3 rd day post intervention. Total scores were calculated and pre and post scores were compared (Flow chart 1).

\section{STATISTICAL ANALYSIS}

Data was computed and analyzed using SPSS (statistical package for social sciences) software version 16 . For different quantitative parameters mean and standard deviations were calculated. Tests of significance namely Paired t-test was used to compare between pre and postintervention.

Table 1: Demographic data

\begin{tabular}{lll}
\hline Age & $24.2 \pm 4.84$ & $18-39$ years \\
BMI & $26.4 \pm 3.51$ & $20-36$ years \\
\hline
\end{tabular}

Table 2: Total experimental group score

\begin{tabular}{ll}
\hline Preintervention (day 1) & $60.2 \pm 23.14$ \\
Postintervention (day 3) & $87.5 \pm 11.14$ \\
Mean difference & $27.3 \pm 14.29$ \\
Paired t-test & 10.486 \\
p-value & $<0.001$ \\
\hline
\end{tabular}

Flow Chart 1: Methodology

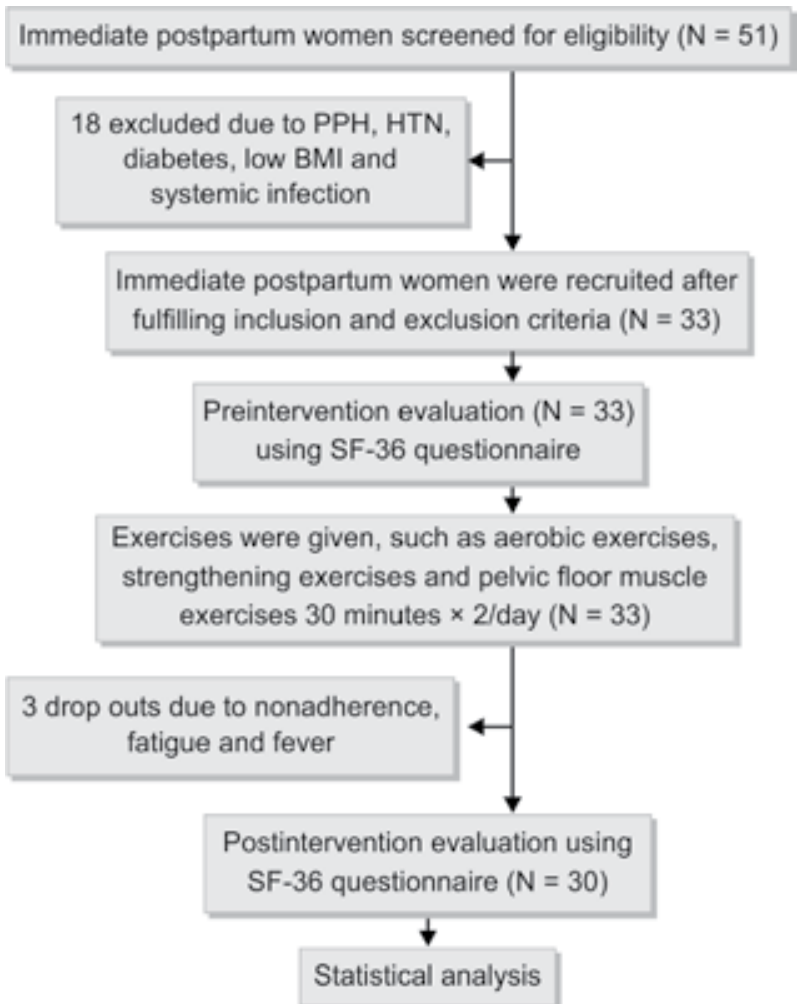

\section{RESULTS}

Age: The mean age of the study participants was 24.2 years with a standard deviation of \pm 4.84 years. BMI: The mean BMI was 26.4 with a standard deviation of \pm 3.51 (Table 1 ).

The preintervention total score of SF- 36 on the 1 st day was $60.2 \pm 23.14$ and postintervention total score SF-36 on the 3rd day was $87.5 \pm 11.14$. There was statistically significant difference in SF-36 score on 3rd day with $p<0.001$ suggesting improvement in quality of life (Table 2).

The preintervention SF-36 on the 1st day for the physical domain, mental domain, social domain, general health domain were $45.7 \pm 28.28,71.5 \pm 30.67,64.4 \pm 21.33$, $69.8 \pm 15.41$ respectively and post intervention SF-36 on the 3 rd day were $86.2 \pm 15.20,94.7 \pm 65.3,84.9 \pm 12.27$, $87.8 \pm 11.01$ respectively. There was a statistically significant difference in SF-36 score on 3rd day with $p<0.001$ in all the above mentioned domains suggesting improvement with postpartum exercises (Table 3 ).

\section{DISCUSSION}

The result of the present study indicate that, postpartum women who received postnatal exercises immediately after delivery have shown to have a better physical well-being and improved quality of life as measured by the SF-36 questionnaire. A study done by Dewey KG, McCrory MA stated that moderate aerobic exercise is safe and beneficial for most postpartum women, and has no effect on lactation 


\begin{tabular}{|c|c|c|c|c|}
\hline & $\begin{array}{l}\text { Physical } \\
\text { domain } \\
\text { (14) }\end{array}$ & $\begin{array}{l}\text { Mental } \\
\text { domain (8) }\end{array}$ & $\begin{array}{l}\text { Social } \\
\text { domain (6) }\end{array}$ & $\begin{array}{l}\text { General } \\
\text { health (8) }\end{array}$ \\
\hline $\begin{array}{l}\text { Pre- } \\
\text { intervention } \\
\text { (day 1) }\end{array}$ & $45.7 \pm 28.28$ & $71.5 \pm 30.67$ & $64.4 \pm 21.33$ & $69.8 \pm 15.41$ \\
\hline $\begin{array}{l}\text { Post- } \\
\text { intervention } \\
\text { (day 3) }\end{array}$ & $86.2 \pm 15.20$ & $94.7 \pm 65.3$ & $84.9 \pm 12.27$ & $87.8 \pm 11.01$ \\
\hline $\begin{array}{l}\text { Mean } \\
\text { difference }\end{array}$ & $40.5 \pm 19.61$ & $23.2 \pm 25.42$ & $20.5 \pm 12.65$ & $18 \pm 9.48$ \\
\hline $\begin{array}{l}\text { Paired } \\
\text { t-test }\end{array}$ & 11.321 & 5.006 & 8.855 & 10.437 \\
\hline$p$-value & $<0.001$ & $<0.001$ & $<0.001$ & $<0.001$ \\
\hline
\end{tabular}

as there is minimal production of lactic acid in milk with this intensity if appropriate guidelines are followed..$^{9}$ In the present study the exercises given to the postpartum women were of mild to moderate intensity in consistent with the above mentioned guidelines. Early ambulation is an accepted puerperal practice. The many confirmed advantages of early ambulation include less frequent bladder complications and constipation, reduces the frequency of puerperal venous thrombosis and pulmonary embolism. Supervised walking is advised in immediate postpartum period hence in the present study women included in the study were administered with supervised walking. ${ }^{13}$ Many studies have shown that pelvic floor muscle exercises given during the immediate postpartum period after vaginal delivery prevent stress urinary incontinence and strengthen pelvic floor muscles. The present study intervention also included pelvic floor muscle training to improve pelvic floor muscle strength and to prevent urinary incontinence in late postpartum period. Also as pelvic floor muscles are a part of core stability it is important to begin exercising the muscles at it earliest. Bahadoran et al in a semi experimental study on postpartum women concluded that the experimental group scored more than the control group. The experimental group intervention included only making the subjects watch a video on postnatal exercises and an educational pamphlet whereas the control group had no intervention. ${ }^{4}$ The present study on the contrary has addressed individual postpartum women and has included supervised postnatal exercises like aerobic exercise, strengthening exercise and pelvic floor muscle exercise which are routinely followed and proved to be beneficial. Koltyn KF, Schultes SS concluded that aerobic exercise given in the postpartum period reduces their anxiety and depression significantly. ${ }^{14}$ An exploratory study result done by Carolyn $\mathrm{M}$ et al also indicated that physical and psychological benefits may accrue to postpartum women who are able to exercise and avoid decreasing their usual level of activity. ${ }^{15}$ The prevalence of maternal blues, postpartum depression and postpartum psychosis is very common. ${ }^{13,16}$ In our study we found physical and psychological benefits in the postpartum women because of postnatal exercises, which indulged them in resuming to their normal physical activity and being psychologically and physically occupied. Exercising also reduces the detrimental effect of immobility which in turn prevents and reduces musculoskeletal pain and stiffness. This could probably be the reason why maternal blues are less common in women who engage themselves in postnatal exercise programs as stated by other inquiries. In a study done by D. Da Costa et al stated that poorer aerobic capacity emerged as independent contributor to physical status. ${ }^{17}$ Thus, in the present study, aerobic exercise in the form of brisk walking helped improve postpartum quality of life. The improvement in mental and physical domains of SF-36 questionnaire supports that aerobic exercise and strengthening exercise have a decrement in anxiety and depression in postpartum women. The exercise intervention in immediate postpartum mothers improved their quality of life in terms of physical, mental, social and general wellbeing. This is very important consideration in terms of reducing maternal blues by engaging them in physical activity and maintaining their general health which in turn will help in better nursing of the infants. Also, women who indulge in physical exercises immediately after postpartum can resume their jobs and activities to the earliest. CJ McCabe et al compared General Health Questionnaire-12 and SF-36 mental domain and concluded that SF- 36 mental domain has psychometric performance compared to GHQ-12 and can be used to compare mental health in a defined population, and it also forms a part of a general health measure and is shorter. ${ }^{18}$ Therefore, in the present study we preferred SF-36 questionnaire as an outcome measure because it was easier to administer, less time consuming, and was sensitive to general health status as well as physical, mental and social status of an individual.

\section{CONCLUSION}

Postnatal exercises administered during immediate postpartum period helps improve the quality of life by improving physical, mental, social and general wellbeing.

\section{ACKNOWLEDGMENT}

We are very grateful and extend our sincere thanks to Prof SA Raddi, Vice President, Society of Midwives, India; Principal and Professor, Department of Obstetrics and Gynecology, KLE University's Institute of Nursing Sciences, Belgaum- 590010, Karnataka, India, for patiently sharing her valuable editorial skills in generating this article. 


\section{REFERENCES}

1. Mantle J, Haslam J, Barton S. Physiotherapy in obstetrics and gynecology. Second edition. Butterworth Heinemann 2004.

2. Bennett R, Brown L. Myles Textbook for Midwives. Philadelphia: Churchill Livingston 1999.

3. Kisner C, Colby LA. Therapeutic Exercise Foundations and Techniques. 5th ed. FA. Davis Company 2007.

4. Bahadoran $P$, et al. Evaluating the effect of exercise on postpartum quality of life. Iranian J Nursing and Midwifery Research Winter 2007;12(1):17-20.

5. O'Hara M, Swain A. Rates and risk of postpartum depression: a meta-analysis. International Review of Psychiatry 1996; 8:37-54.

6. ACOG Committee Opinion 2002 Jan;267.p.1-3.

7. Joint SOGC/CSEP Clinical Practice Guideline 2003 June; 129:p.1-7.

8. Stephenson RGO, Connor LJ. Obstetrics and gynecologic care in physical therapy. Second Edition. SLACK Incorporated 2000.

9. Dewey KG, McCrory MA. Effects of dieting and physical activity on pregnancy and lactation. Am J Clin Nutr 1994 Feb;59(2 Suppl):446S-452S; discussion 452S-453S.

10. Dewey KG, et al. A randomized study of the effects of aerobic exercise by lactating women on breast: milk volume and composition. The New England Journal of Medicine 1994;330(7): 449-453.
11. Sampselle CM, Seng J, Yeo S, et al. Physical activity and postpartum well-being. J Obstet Gynecol Neonatal Nurs 1999; 28:41-49.

12. Ware J. E. SF- 36 Health Survey Update. SPINE 2000;25(24): 3130-3139.

13. Cunningham FG, et al. Williams Obstetrics. 22nd ed. United States of America: McGraw-Hill 2005.

14. Koltyn KF, Schultes SS. Psychological effects of an aerobic exercise session and a rest session following pregnancy. J Sports Med Phys Fitness 1997 Dec;37(4):287-291.

15. Carolyn M, Sampselle, Seng J, Yeo S, Killion C, Oakley D. Physical activity and postpartum well-being. J Obstet Gynecol Neonatal Nurs 1999 Jan;28(1):41-49.

16. Kumar R. Postnatal mental illness: a transcultural perspective. Social Psychiatry and Psychiatric Epidemiology 1994;29(6): 250-264.

17. Costa DDa, Drista M, Rippen N, Lowensteyn I, Khalife S. Health related quality of life in postpartum depressed women. Archives of women's mental health. March 2006;9(2):95102.

18. McCabe CJ, Thomas KJ, Brazier JE, Coleman P. Measuring the mental health status of a population: a comparison of the GHQ-12 and the SF-36 (MHI-5). The British Journal of Psychiatry 1996; 169:516-521. 